\title{
Justification of the Disk Tool Application for Working Bodies of Mining Machines
}

\author{
Alexey Khoreshok ${ }^{1,}$, Leonid Mametyev ${ }^{1}$, Valery Nesterov ${ }^{1}$, Aleksandre Tsekhin ${ }^{1}$, and \\ Andrey Borisov ${ }^{1, *}$ \\ ${ }^{1}$ T.F. Gorbachev Kuzbass State Technical University, Department of Mining Machines and \\ Complexes, 650000 Kemerovo, 28 Vesennya st., the Russian Federation
}

\begin{abstract}
The dynamics analysis of coal mining and mine workings in Russia and Kuzbass was made with an assessment of operational productivity and load on fully-mechanized long-walls (FMLW). The article presents statistical data on the average number of FMLW and average monthly productivity of a miner. Disadvantages in the cutters work of working bodies of shearers and tunnelling machines during the mining of seams with a solid rock inclusions were determined. The usage of a disk tool instead of a cutter of working bodies of mining machines at operation at the mining enterprises of Kuzbass was offered in the article. The article recommends to expand the area of application of the mechanical method of coal seams and rocks destruction with a breaking down point of uniaxial compression up to $100 \mathrm{MPa}$ by using a biconic disk tool of working bodies of extracting machines. Shearers' tractive characteristics during mining of coal seams with rock inclusions, allowing to determine the energy intensity of destruction process by a disk tool were obtained. The options of design implementation of unified attachment points of a disc tool of working bodies of mining machines are presented. It was established that the main advantages of a disk tool over the cutter are the implementation of reversible modes of operation of working bodies, hardening and reducing dust level in face space.
\end{abstract}

\section{Introduction}

Improvement of working bodies of tunnelling machines and shearers and also drilling machines at a rational combination, cutters [1-5] and disk tools [6-19] fixation and arrangement is a multipurpose task to implement the principle of coal destruction and solid rocks with large cleavage. At the same time, a disk tool can combine different design and geometric parameters, that allow to expand the application of tunnelling machines within the mechanical method of destruction of solid and abrasive rocks.

Currently, the rational energy consumption within the expansion of mining machines of various design usage is one of the basic directions of improvement and modernization of their working bodies.

\footnotetext{
* Corresponding author: borisovau@kuzstu.ru
} 


\section{Researches}

In 2018 in Russia, it was mined 439.3 million tons, which is $7 \%$ more than a year earlier. The underground method gave 108.3 million tons, which is $3 \%$ more than a year earlier. In Kuzbass it was mined 255.3 million tons in total, which is $6 \%$ more than a year earlier. Coal mining by "SUEK" in 2018 was 110.326 million tons, which is $2.2 \%$ more than a year earlier, while "SUEK-Kuzbass" retained mining at the level of 2017. To maintain the extraction front in Russia in 2018, $441.8 \mathrm{~km}$. of mine workings were held, which is $1 \%$ more than in 2017 , including $358.5 \mathrm{~km}$. of opening and preparing mine workings, which is $3 \%$ more than in 2017 . The level of a shearer drifting was $91 \%$ of the total amount of underground mining. Table 1 presents the summarized data of the coal mining in Russia and in Kuzbass since 2013 to 2018 [20].

Table 1. Dynamics of coal mining (million tons) in Russia and Kuzbass since 2013 to 2018

\begin{tabular}{|l|c|c|c|c|c|c|c|}
\hline \multicolumn{1}{|c|}{ Years } & & 2013 & 2014 & 2015 & 2016 & 2017 & 2018 \\
\hline Russia & & & & & & & \\
- overall output & & 352.1 & 358.2 & 374 & 386.9 & 408.9 & 439.3 \\
- underground method & & 101.3 & 105.3 & 103.6 & 104.3 & 105.4 & 108.3 \\
\hline Kuzbass (overall output) & & 202.7 & 211.6 & 216.2 & 227.9 & 241.1 & 255.3 \\
\hline "SUEK" (overall output) & & 96.452 & 98.860 & 97.756 & 105.375 & 107.778 & 110.326 \\
\hline "SUEK-Kuzbass" & & 32.615 & 33.094 & 30.052 & 37.715 & 38.21 & 37.842 \\
\hline
\end{tabular}

In 2018 in Kuzbass, 255.3 million tons of coal were mined, which is 14 million tons more than a year earlier. At the same time, the mines produced 89.5 million tons of coal, which is 4.6 million tons more than in 2017 and coal supply from Kemerovo region was carried out into 64 countries. The amount of underground mining and data about productivity and load upon a face in Russia, Kuzbass since 2013 to 2018 are shown in tables 2, 3 [20].

Table 2. Underground mining $(\mathrm{km})$ in Russia since 2013 to 2018

\begin{tabular}{|l|c|c|c|c|c|c|}
\hline \multicolumn{1}{|c|}{ Years } & 2013 & 2014 & 2015 & 2016 & 2017 & 2018 \\
\hline Total & 395.5 & 359 & 344 & 376 & 403.1 & 441.8 \\
\hline Opening and preparing & 319.5 & 292 & 274 & 292.2 & 348.8 & 358.5 \\
\hline $\begin{array}{l}\text { Level of shearer drifting of the } \\
\text { total amount of underground mining, \% }\end{array}$ & 86 & 89 & 93 & 92 & 91 & 91 \\
\hline
\end{tabular}

Table 3. Productivity and load upon a face (t) in Russia and Kuzbass since 2013 to 2018

\begin{tabular}{|l|c|c|c|c|c|c|}
\hline \multicolumn{1}{|c|}{ Years } & 2013 & 2014 & 2015 & 2016 & 2017 & 2018 \\
\hline $\begin{array}{l}\text { Average daily coal mining from } \\
\text { one operating highwall mining } \\
\text { - on average of industry }\end{array}$ & 3605 & 4053 & 4247 & 4594 & 4767 & 4827 \\
\hline - in Kuznetsk basin & 3885 & 4554 & 4952 & 5443 & 5725 & 5599 \\
\hline - "SUEK-Kuzbass" & 9602 & 8895 & 9998 & 11513 & 12849 & 10843 \\
\hline $\begin{array}{l}\text { Average daily load on the } \\
\text { complex-mechanized highwall } \\
\text { mining on average of industry }\end{array}$ & 4166 & 4282 & 4476 & 4871 & 5105 & 5006 \\
\hline
\end{tabular}

The contact strength of Kuznetsk basin rocks varies from 250 to $3800 \mathrm{MPa}$. The rocks with contact strength $\mathrm{P}_{\mathrm{k}}=3000-4500 \mathrm{MPa}$ are very rare in the basin. The abrasiveness of the rocks varies in a wide range in value of the coefficient of abrasiveness (a) from 0.43 to 1.63 . 
In general, the annual amount of mining is $70-80 \mathrm{~km}$ of preparatory mine workings with the usage of tunnelling machines of selective action in "SUEK-Kuzbass" mines. Further increase of the amount of coal mining by underground method leads to necessity to increase the pace and efficiency of preparatory underground mining. In addition, this requires the expansion of the area of application and increase of operational reliability in the operation of tunnelling machines of selective action in structurally inhomogeneous coal faces.

\section{Results and discussion}

Now a rock-cutting tool has become widely spread to equip working bodies of shearers, tunnelling and drilling machines [1-5]. An important index that characterizes the efficiency of the tunnelling machines is the application of a cutting tool, since it affects the cost of mining and the productivity of the machine, because to replace the worn working tool it is necessary to stop the machine, which reduces the machine readiness factor. With the increase in the specific application rate of cutters, the operation of the working body with a partially worn tool probability increases, which leads to an increase in the energy intensity of the destruction process, an increase in dynamic loads and equipment accidents. This is especially true when working on solid inclusions is done.

Thus, the work of tunnelling machines, equipped with working bodies with a cutting tool, in the development of layers with solid inclusions has a number of disadvantages: high wear and expenditure of a tool; high work dynamics; low application efficiency of machines for workings in layers containing a large number of solid rock inclusions with high abrasiveness. Moreover, the process of destruction in these conditions is accompanied by a large volume of small fractions of destroyed coal or rock with high dust content in air.

One of the ways to create an effective rock-breaking tool is the usage of a disk tool [619], which was used for working bodies of the shearers, tunnelling and drilling machines and which can be used for the mechanical method of destruction of coal seams and rock in the range of compressive strength $\sigma_{\text {compress }}$ up to $100 \mathrm{MPa}$.

The KuzSTU Department of Mining Machines and Complexes carried out complex studies on full-size laboratory benches and the experimental design of the working bodies of mining machines with a disc rock cutting tools were tested in mining conditions (Fig. 1).

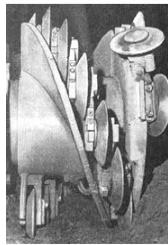

a

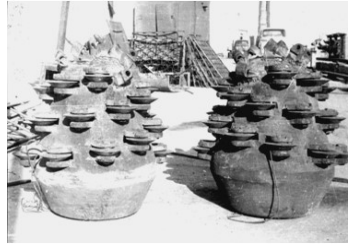

b

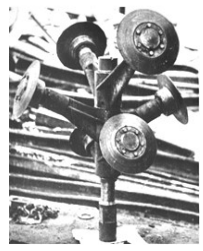

c

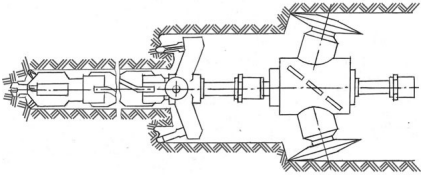

d

Fig. 1. The usage of a disk tool for the working bodies of mining machines: $a-$ screw; $b$ - crowns; expanders: (c) - reverse expander; (d) - forward two-stage expander.

Fig. 1 shows a general view of the experimental screw working body of a shearer with a disk tool, which during tests showed that it could be used in a wider range of mining and geological conditions in comparison with serial samples.

The basic power and energy indexes of destruction processes of coal seams with solid inclusions by a disk tool are shown in Fig. 2, 3.

Fig. 2 shows that in the operation modes (capture value $B=0.63 \mathrm{~m}$ ) of machine operation with an experimental screw, there is a decrease in power consumption $\mathrm{N}$ by $25-30 \%$, and the energy intensity $\mathrm{H}_{\mathrm{w}}$ by $24-32 \%$. Especially this effect can be seen under the feed speed $\mathrm{V}>1.5 \mathrm{~m} / \mathrm{min}$. There was an effort in the traction body. Thus, feed 
force increases in 1.7 ..2.0 times under self-cutting, and when coal is extracted $(\mathrm{B}=0.63 \mathrm{~m})$ feed force increases in 1.25...1.30 times.

In addition, it was founded that the increase in the step of a tool of the working body leads to an improvement in the coal rank. The amount of breaze of class $-6 \mathrm{~mm}$ decreased by $14.4 \%$ under the significant increase in the amount of coal class $+100 \mathrm{~mm}$, which is provided not only by the use of the operation of a disk shearing tool (shearing instead of cutting), but also by the scheme of the working tool set, forming shear of the useful mineral of a large cross section.

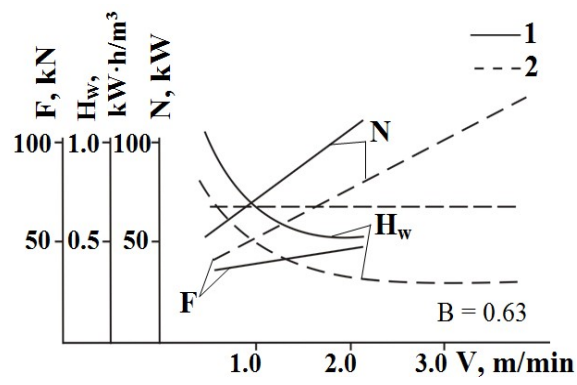

Fig. 2. Traction characteristics of a shearer during mining of coal seams with inclusions: serial working body (1) and experimental working body (2)

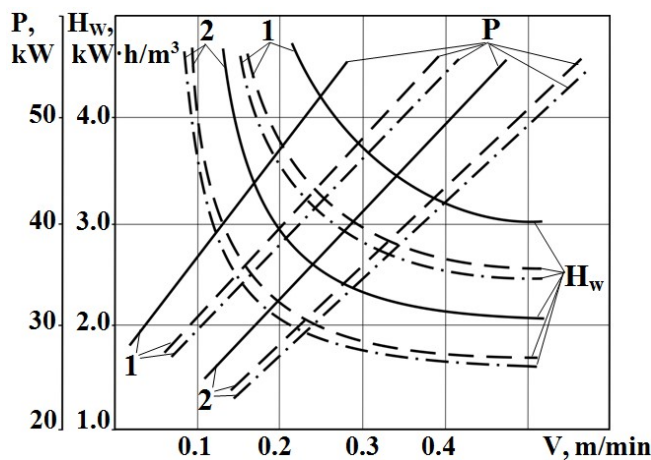

Fig. 3. Dependences of the P power, consumed by the electric motor of the tunnelling machines and the energy intensity $\mathrm{H}_{\mathrm{w}}$ destruction of the massif on the feed speed V

In the article [6] the authors recommend to expand the areas of application of a disk tool by equipping radial crowns of tunnelling machines of selective action with it (Fig. 1, b).

Fig. 3 shows the results of experimental studies: 1 - for solid inclusions; 2 - for sand and clay rocks;

- mining by serial working body;

- - - mining by experimental working body of the 3rd type;

- - - - mining by experimental working body of the 4-th type.

The general graphic analysis shows that during the machine operation with experimental working bodies in comparison with the serial, the $\mathrm{P}$ power consumption and the energy intensity $\mathrm{H}_{\mathrm{w}}$ decreased by an average of 14-18\%, but during machine working with sand and clay rocks without solid inclusions reduction of these indicators is $8-10 \%$.

Energy intensity $\mathrm{H}_{\mathrm{w}}$ and $\mathrm{P}$ power consumption decreased respectively 6-7 \% and 3-4 \% when comparing the $3^{\mathrm{d}}$ and $4^{\text {th }}$ experimental samples. When working on a seam with solid inclusions, which make up about $20 \%$ of the face area, the total decrease for both experimental samples was $14-16 \%$, but with the content of solid inclusions up to $40-50 \%$ the decrease in energy indicators reached $24-28 \%$.

Comparison of experimental working bodies shows that the working body of the $4^{\text {th }}$ type has advantages over the $3^{\mathrm{d}}$ type when working in layers with solid inclusions $\sigma_{\text {compress }}>$ $50 \mathrm{MPa}$ by increasing the face processing speed, and consequently, its productivity [6].

The works, the results of which characterize the prospects for the use of a disk rockcutting tool for extenders for drilling of large diameter rising wells are of additional interest. 
Now, technical solutions to improve the design of working bodies of mining machines with a disk tool for the reversible operation modes implementation have been developed at KuzSTU Department of Mining Machines and Complexes (Fig. 4).

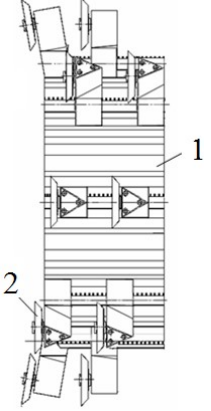

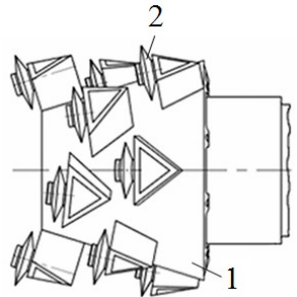

$\mathrm{b}$

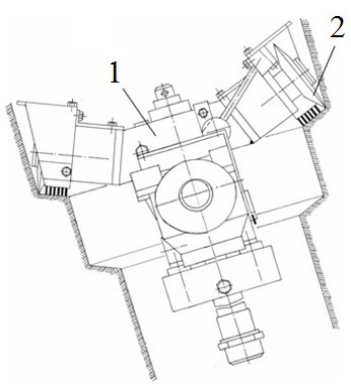

Fig. 4. The working bodies with the cantilever attachment point of a disk tool to the trigonal prisms: a - screw; b-crown; c-expander; 1 - body; 2 - prism

At the same time, special attention is paid to improving the design of the cantilever attachment points of a disk rock-cutting tool to multi-faceted prisms of the working bodies of mining machines [6-9]. A set of original technical solutions proved by patents of the Russian Federation: 2455486, 128898, 134586, 136086, 138704, 141339, 146845, 149617, $152701,160664,182774,183759,187566,188154$ were developed to improve technical and economic indicators of operation processes of the shearer, tunnelling machines and drilling machines in a wide range of physical and mechanical properties of the destructible coal faces.

\section{Conclusion}

The usage of a disk tool for working bodies of mining machines allows operating it effectively in unregulated conditions - under development of coal seams with layers and large consolidated inclusions.

The experience of disk tool usage in Kuzbass mines showed an increase in service life and wear resistance with a decrease in the number of its replacements and the cost of installation and dismantling operations at the place of operation. In addition, advantages of a disk tool in comparison with a cutter are connected with realization of reversible operation modes of working bodies of mining machines.

\section{References}

1. X. J. Li et al., Appl. Mech. Mater. 556:562, 498 (2014)

2. S.A. Prokopenko, Appl. Mech. Mater. 682, 319 (2014)

3. S. Prokopenko, A. Sushko, I. Kurzina, IOP Conf. Ser.: Mater. Sci. Eng. 91, 012058 (2015)

4. P.D. Krestovozdvizhensky, V.I. Klishin, S.M. Nikitenko, P.B. Gerike, J. Min. Sci. 51:2, $323(2015)$

5. S.A. Prokopenko, V.S. Ludzish, I.A. Kurzina, J. Min. Sci. 52:1, 153 (2016)

6. A. Khoreshok, L. Mametyev, A. Borisov, A. Vorobiev, Taishan academic forum project on mine disaster prevention and control. Chinese coal in the XXI century: Mining, green and safety, 177 (2014) 
7. A.A Khoreshok, L.E. Mametyev, A.Yu. Borisov, A.V. Vorobyev, IOP Conf. Ser.: Mater. Sci. Eng. 91, 012084 (2015)

8. A.A. Khoreshok, L.E. Mametev, A.Yu. Borisov, A.V. Vorobev, Appl. Mech. Mater. 770, 429 (2015)

9. A.A. Khoreshok, L.E. Mametev, A.Yu. Borisov, A.V. Vorobev, Appl. Mech. Mater. 770, 434 (2015)

10. P.B. Gerike, M.A. Belikov, J. Min. Sci. 39:2, 162 (2003)

11. B.L. Gerike, P.B. Gerike, A.P. Filatov, V.I. Klishin, J. Min. Sci. 42:6, 610 (2006)

12. B.L. Gerike, P.B. Gerike, V.I. Klishin, A.P. Filatov, J. Min. Sci. 44:5, 497 (2008)

13. B.L. Gerike, V.I. Klishin, P.B. Gerike, J. Min. Sci. 52:3, 481 (2016)

14. X.H. Li, W. Du, Z.L. Huang, W.L. Fu, Appl. Mech. Mater. 127, 385 (2011)

15. F.H. Li, Z.X. Cai, Y.L. Kang, Appl. Mech. Mater. 90:93, 2232 (2011)

16. L.T. Man and S. J. Li, Adv. Mater. Res. 366, 224 (2012)

17. K.R. Hong et al., Adv. Mater. Res. 399:401, 2116 (2012)

18. A.N. Zhang, Z.F. Zhu, F. Zhu, Adv. Mater. Res. 791:793, 742 (2013)

19. Y. Zhang, X.W. Wang, H.F. Liu, Appl. Mech. Mater. 487, 513 (2014)

20. I.G. Tarazanov, Ugol 3, 64 (2019) 